\title{
Coeficientes de metabolizabilidade da energia bruta de diferentes ingredientes para frangos de corte
}

\author{
Ricardo Vianna Nunes ${ }^{1 *}$, Horacio Santiago Rostagno ${ }^{2}$, Paulo Cezar Gomes ${ }^{2}$, Christiane \\ Garcia Vilela Nunes ${ }^{1}$, Paulo Cesar Pozza ${ }^{1^{*}}$, Marcelle Santana de Araujo ${ }^{1}$
}

1 Pós-Graduação Departamento de Zootecnia, UFV - 36571-000 - Viçosa, MG.
2 Departamento de Zootecnia, UFV - 36571-000 - Viçosa, MG. Bolsista do CNPq.

RESUMO - Com o objetivo de determinar os valores de energia metabolizável aparente (EMA), aparente corrigida $\left(E_{n}\right)$, verdadeira $(E M V)$ e verdadeira corrigida $\left(E M V_{n}\right)$ de oito ingredientes e seus respectivos coeficientes de metabolizabilidade, foram utilizados 300 frangos de corte machos Ross, com 21 dias de idade, distribuídos em oito tratamentos (alimentos) e uma ração-referência, em três blocos com duas repetições por bloco e cinco aves por unidade experimental. Os alimentos avaliados foram: duas amostras de grão de trigo (TI), duas de farelo de trigo (FT), duas de grão de milho (MI), uma de grão de sorgo (SO) e uma de farelo de glúten de milho 21\% (21\% FGM), as quais substituíram 30\% da ração-referência. As aves receberam ração à vontade por 12 dias, de modo que os cinco dias finais foram destinados à coleta de excretas. Durante os cinco dias de coleta, 30 aves distribuídas em seis gaiolas foram mantidas em jejum por 72 horas (as 24 horas iniciais para esvaziamento do trato gastrointestinal e as 48 horas restantes para coleta das excretas), que foram quantificadas e extrapoladas para cinco dias. Os valores de EMA e EMA , em kcal/kg MS, foram em média de 3.391 e 3.275 para o TI, de 2.076 e 1.996 para o FT, de 3.862 e 3.768 para o MI, de 3.551 e 3.464 para o SO e de 1.992 a 1.901 para o 21\% FGM. Os valores de EMV e EMV , em $\mathrm{kcal} / \mathrm{kg}$ MS, foram em média de 3.495 e 3.496 para o TI, de 2.195 e 2.146 para o FT, de 3.981 e 4.040 para o MI, de 3.652 e 3.680 para o sorgo e de 2.117 a 1.961 para o 21\% FGM. Os coeficientes de metabolizabilidade para energia bruta foram em média de $68,94 \%$.

Palavras-chave: coeficientes de metabolizabilidade, energia metabolizável aparente, energia metabolizável verdadeira

\section{Coefficient of metabolizability of gross energy of different ingredients for broiler chickens}

\begin{abstract}
With the objective of determine the apparent metabolizable energy (AME), corrected apparent (AME ${ }_{n}$ ), true metabolizable energy (TME) and corrected true $\left(\mathrm{TME}_{\mathrm{n}}\right)$ values of eight feedstuffs and their respective coefficient of metabolizability, 300 male broiler chickens, Ross, averaging 21 days old, were assigned to eight treatment (feeds) and one reference diet, in three blocks with two replications per block and five birds per experimental unit. The feedstuffs studied were: two sample of wheat grain (WG), two wheat bran (WB), two corn grain (CG), one of sorghum grain (SG) and one of corn gluten feed $21 \%$ (21\% CGF), which replaced $30 \%$ of the reference diet. The birds were ad libitum fed per 12 days, where the last five days were used for the excreta collection. During the five days of collection, 30 birds allotted to six cages were fasted for 72 hours (the initial 24 hours for the emptying of the gastrointestinal tract) and the remaining 48 hours, for excreta collection, which was quantified and extrapolated for five days. The AME and $\mathrm{AME}_{\mathrm{n}}$ in $\mathrm{kcal} / \mathrm{kg} \mathrm{DM}$, were in average of 3.391 and 3.275 for WG, of 2.076 and 1.996 for WB, of 3.862 and 3.768 for CG, of 3.551 and 3.464 for SG and of 1.992 and 1.901 for $21 \%$ CGF. To TME and $\mathrm{TME}_{\mathrm{n}}$ in kcal/kg DM, were in average of 3.495 and 3.496 for WG, of 2.195 and 2.146 for WB, of 3.981 and 4.040 for CG, of 3.652 and 3.680 for SG and of 2.117 and 1.961 for $21 \%$ CGF. The coefficient of metabolizability for gross energy were in average of $68,94 \%$.
\end{abstract}

Key Words: apparent metabolizable energy, coefficient of metabolizability, true metabolizable energy

\section{Introdução}

A avicultura é uma atividade dinâmica que fornece proteínas de origem animal de alta qualidade para consumo humano. Atualmente, o Brasil se mantém em ótima posição no ranking mundial de produção avícola, conquistada com a adoção de tecnologias modernas ao longo das últimas décadas.

Este artigo foi recebido em 12/6/2006 e aprovado em 9/8/2007. 
Na nutrição, a qualidade dos ingredientes tem merecido especial atenção visando formular rações com maior precisão (Said, 1995) e de menor custo, uma vez que a alimentação corresponde a grande parte do custo total na produção de frangos de corte. A formulação e o balanceamento de rações consistem na mistura de vários alimentos com a finalidade de atender às exigências nutricionais dos animais para que possam expressar seu máximo potencial genético. A composição química e energética dos alimentos determina seu valor nutricional e suas limitações nutricionais.

A grande variação na composição dos alimentos disponíveis no Brasil, decorrente de diversos fatores, é um problema enfrentado pelos nutricionistas. Assim, vários trabalhos têm sido desenvolvidos com o objetivo de atualizar e tornar mais precisos os valores nutricionais dos alimentos comumente utilizados nas rações das aves e de conhecer o valor nutricional de novos alimentos, tornando as tabelas mais completas e com valores mais precisos. A produção de novas variedades de milho, trigo e sorgo tem ocorrido naturalmente. Híbridos de milho com alto teor de óleo (5 a 8,5\% de EE) e alto teor de lisina podem ser encontrados no Brasil. A produção de sorgo visando à redução do teor de tanino pode resultar em variedades com composição química diferenciada; o mesmo que ocorre na produção de trigo e de seus subprodutos.

Existem tabelas que descrevem a mesma composição química desses alimentos, entretanto, fornecem resultados médios de análises de diferentes híbridos ou variedades. A variabilidade na composição química dos alimentos pode influenciar os valores energéticos e resultar em diferenças nos valores de energia metabolizável (EM), atribuídas a condições ambientais durante a produção dos grãos, a diferenças genéticas e a interação ambiente $\times$ genética.

O conhecimento do conteúdo energético dos alimentos é fundamental para os nutricionistas, uma vez que os ingredientes são incluídos ou rejeitados nas formulações de mínimo custo de acordo com seu conteúdo de energia (Lima, 1996). A energia metabolizável (EM) é a melhor forma de se expressar a energia disponível para as aves e a mais utilizada nos cálculos do valor nutricional de rações. Os primeiros estudos realizados por Hill \& Anderson (1958) permitiram o uso da EM no cálculo de rações para aves em substituição à energia produtiva até então utilizada. Esses autores observaram que os valores de EM foram menos variáveis que os de energia produtiva.

A energia é fundamental para aves e um componente importante em todos os alimentos, portanto, o controle da produtividade, a eficiência e a rentabilidade exige conhecimento mais detalhado das exigências e dos valores energéticos de cada alimento (Sibbald, 1982). Segundo Freitas et al. (2006), na formulação de rações, a principal preocupação é fornecer energia em quantidade adequada para as aves. Para isso, é necessário conhecer o valor energético dos alimentos. Kolling et al. (2005) relataram que o fornecimento de dietas altamente energéticas resulta em carcaças mais gordas, enquanto dietas com alto teor de proteína resultam em carcaças mais magras. Dietas com relações calórico-protéicas mais amplas (menos proteína) promovem maior consumo de energia ou baixa ingestão de proteína. Por outro lado, em dietas com relações mais estreitas (mais proteína) promovem menor consumo de energia e carcaças mais magras (Bartov, 1998).

Este trabalho foi conduzido com o objetivo de determinar os valores de energia metabolizável aparente (EMA), energia metabolizável aparente corrigida pelo balanço de nitrogênio (EMA ${ }_{n}$ ), energia metabolizável verdadeira (EMV) e energia metabolizável verdadeira corrigida pelo balanço de nitrogênio $\left(E M V_{n}\right)$ e os respectivos coeficientes de metabolizabilidade de diferentes alimentos para aves.

\section{Material e Métodos}

Um ensaio biológico foi realizado no Setor de Avicultura do Departamento de Zootecnia (DZO) da Universidade Federal de Viçosa (UFV), MG, no período de 28/11/2001 a 10/2/2002 utilizando-se o método tradicional de coleta total de excretas.

A temperatura média pela manhã no interior da sala de metabolismo foi de 21,8 e 28, $8^{\circ} \mathrm{C}$ (mínima e máxima, respectivamente). Durante a tarde, a temperatura média oscilou de 23,6 a $29,2^{\circ} \mathrm{C}$, respectivamente, para mínima e máxima. A porcentagem de umidade relativa média do ar no interior da sala de metabolismo foi de 70,8 às 8 h e de $45,0 \%$ às $17 \mathrm{~h}$.

Foram avaliados oito ingredientes de origem vegetal, provenientes de diferentes fornecedores e constituídos de duas amostras de milho em grão, trigo em grão e farelo de trigo e de uma amostra de sorgo em grão e de farelo de glúten de milho 21\%.

As análises químicas dos alimentos foram realizadas no Laboratório de Nutrição Animal da Universidade Federal de Viçosa para determinação dos valores de matéria seca (MS), nitrogênio (N), extrato etéreo (EE), fibra bruta (FB), fibra em detergente neutro (FDN), fibra em detergente ácido (FDA), cinzas, Ca, P e Mg, segundo técnicas descritas por Silva \& Queiroz (2002). Para determinação dos açúcares solúveis, utilizou-se a metodologia descrita por Dubois et al. (1956), citada por Hall (2000). O amido foi determinado no substrato após extração dos açúcares solúveis com álcool etílico 80\% 
e sua extração foi realizada via ácido perclórico 30\% com posterior reação com Reativo de Antrona (Silva \& Queiroz, 2002). Também foi determinado o diâmetro geométrico médio (DGM) das partículas dos alimentos utilizando-se técnica descrita por Zanotto \& Bellaver (1996).

Para determinação dos valores de EM, foram utilizados 300 frangos de corte machos, linhagem Ross 308, com 21 dias de idade e peso médio de 589,20 g. Os tratamentos consistiram de oito alimentos, de modo que cada um substituiu 30\% da ração-referência (Tabela 1), calculada segundo exigências descritas por Rostagno et al. (2000), exceto para proteína bruta (PB), pois os ingredientes utilizados contêm baixos níveis nutricionais de nitrogênio.

O delineamento experimental foi em blocos ao acaso, cada um com duas repetições, nove rações e cinco aves por unidade experimental. Até o $21^{\circ}$ dia de idade, as aves receberam ração inicial para frangos de corte. No $21^{\underline{0}}$ dia de idade, foram transferidas para baterias de estrutura metálica, onde foram mantidas por 12 dias (sete de adaptação e cinco de coleta total das excretas) com água e ração experimental à vontade. As excretas foram coletadas duas vezes ao dia, às $8 \mathrm{~h}$ e $17 \mathrm{~h}$. As aves receberam 24 horas de luz durante todo o período experimental. Ao término do experimento, foi determinada a quantidade de ração consumida por unidade experimental durante os cinco dias de coleta.

Para determinação das perdas fecais endógenas e urinárias metabólicas, 30 aves de mesma idade, sexo e linhagem foram mantidas em jejum, durante 72 horas (as primeiras 24 horas para esvaziamento do aparelho digestivo e as 48 horas restantes para coleta total de excretas). Após o término da última coleta, as excretas foram pesadas e os valores obtidos foram extrapolados para produção de cinco dias de acordo com o período de coleta.

As excretas coletadas durante o experimento foram acondicionadas em sacos plásticos devidamente identificados e armazenadas em freezer $\left(-10^{\circ} \mathrm{C}\right)$ até o final do período de coleta. Posteriormente, foram descongeladas, pesadas e homogeneizadas. Amostras foram retiradas e pré-secas em estufas ventiladas a $55^{\circ} \mathrm{C}$ para análises dos teores MS a $105^{\circ} \mathrm{C}$, de nitrogênio e de energia bruta.

Uma vez obtidos os resultados das análises laboratoriais dos ingredientes, da ração-referência e das excretas, foram calculados os valores de energia metabolizável aparente (EMA), aparente corrigida $\left(\right.$ EMA $\left._{n}\right)$, verdadeira (EMV) e verdadeira corrigida $\left(\mathrm{EMV}_{\mathrm{n}}\right)$ utilizando-se equações propostas por Matterson et al. (1965). Com base nos valores de EM e EB dos ingredientes, foram calculados os coeficientes de metabolizabilidade dos valores energéticos.

Como procedimento estatístico, aplicou-se o teste de comparação de médias Student Newman-Keuls, a 5\% de
Tabela 1 - Composição da ração-referência (\%MN) ${ }^{1}$

\begin{tabular}{|c|c|}
\hline Item & Ração-referência (\%) \\
\hline \multicolumn{2}{|l|}{ Ingrediente } \\
\hline Milho & 49,819 \\
\hline Farelo de soja & 37,968 \\
\hline Farelo de glúten de milho $60 \%$ & 6,500 \\
\hline Óleo vegetal & 1,737 \\
\hline Fosfato bicálcico & 1,533 \\
\hline Calcário & 0,923 \\
\hline Sal & 0,377 \\
\hline Suplemento mineral ${ }^{1}$ & 0,060 \\
\hline Suplemento vitamínico ${ }^{2}$ & 0,130 \\
\hline DL-Met (99\%) & 0,216 \\
\hline Cloreto de colina $(60 \%)$ & 0,060 \\
\hline Anticoccidiano $^{3}$ & 0,055 \\
\hline Promotor de crescimento ${ }^{4}$ & 0,002 \\
\hline Antioxidante ${ }^{5}$ & 0,020 \\
\hline Óxido crômico $\left(\mathrm{Cr}_{2} \mathrm{O}_{3}\right)$ & 0,600 \\
\hline \multicolumn{2}{|l|}{ Composição nutricional calculada } \\
\hline PB (\%) & 25,00 \\
\hline EM (kcal/kg) & 2.950 \\
\hline Met digestível (\%) & 0,608 \\
\hline Met + Cys digestível (\%) & 0,950 \\
\hline Lys digestível (\%) & 1,120 \\
\hline Thr digestível (\%) & 0,858 \\
\hline Trp digestível (\%) & 0,267 \\
\hline Arg digestível (\%) & 1,498 \\
\hline $\mathrm{Ca}(\%)$ & 0,874 \\
\hline P disponível (\%) & 0,406 \\
\hline $\mathrm{Na}(\%)$ & 0,192 \\
\hline K (\%) & 0,859 \\
\hline \multicolumn{2}{|c|}{ 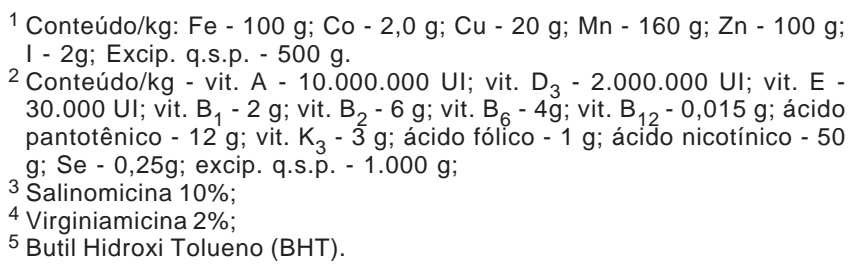 } \\
\hline
\end{tabular}

probabilidade, entre os valores médios dos coeficientes de metabolizabilidade, por meio do Sistema de Análises Estatísticas e Genéticas - SAEG (UFV, 1999).

\section{Resultados e Discussão}

Observou-se grande variação na composição química entre os alimentos estudados (Tabela 1). Esta variação é normal, principalmente em alimentos de origem diferente, mas é menor entre os mesmos alimentos (milho 1 e 2, trigos 1 e 2, farelos de trigo 1 e 2). A variação entre os valores da composição química dos alimentos também foi grande em comparação aos valores descritos nas literaturas nacional (EMBRAPA, 1991; MAARA, 1996; Rostagno et al., 2005) e estrangeira (Scott et al., 1982; Janssen, 1989; NRC, 1994; 1998).

As diferenças entre os ingredientes podem ter sido causadas por vários fatores, entre eles, a variação entre 
solos, clima e tipos de processamento (Albino \& Silva, 1996). O processamento pode afetar não só a composição química como também o valor nutritivo dos alimentos, principalmente a digestibilidade dos nutrientes.

Os teores de PB do milho, do sorgo e do farelo de trigo foram inferiores aos valores propostos por Rostagno et al. (2005) e pelo NRC (1994; 1998), entretanto, o conteúdo de PB do farelo de glúten de milho (21\%) e do trigo foram semelhantes aos valores relatados por esses autores. A variação na porcentagem de amido foi sempre inferior à descrita por Rostagno et al. (2005), com exceção dos farelos de trigo. Entretanto, esta análise foi feita via extração ácida e normalmente possibilita conhecer a quantidade de carboidratos ácidos solúveis. Neste trabalho, as mesmas amostras foram corrigidas por meio da extração dos açúcares solúveis por álcool etílico a $80 \%$.

Os valores de fibra bruta (FB), FDN e FDA, para todos os alimentos estudados, foram semelhantes aos descritos por Rostagno et al. (2005) e apresentaram pequenas variações para mais ou para menos. Em comparação aos relatados por Nunes et al. (2001), os valores de hemicelulose para os trigos 1 e 2 foram 38,00\% maiores. Os trigos grão 1 e 2 são classificados como de média granulometria e os demais como de fina granulometria. Segundo Zanotto \& Bellaver (1996), os alimentos podem ser classificados em partículas finas (DGM <0,60 mm), médias (DGM de 0,60 a 2,00 mm) ou grossas (DGM > 2,00 mm). O tamanho das partículas pode promover alterações no consumo (Penz Jr. et al., 1999) e afetar a utilização da energia (Brugalli et al., 1999), por isso, é importante determinar o tamanho médio das partículas dos alimentos que compõem as rações avícolas.

Os ingredientes estudados diferiram quanto aos valores de EMA, EMA , EMV e EMV $_{n}$, em decorrência das variações em sua composição química (Tabela 4). Os valores de EMA foram de 1.992 a 3.924; os de EMA , de 1.901 a 3.830; os de EMV, de 2.117 a 4.055; e os de EMV ${ }_{\mathrm{n}}$, de 1.961 a $4.122 \mathrm{kcal} / \mathrm{kg}$ de MS. Os valores de EMA foram em média 4,47\% superiores aos de $\mathrm{EMA}_{\mathrm{n}}$, uma característica normal quando os valores de EM são determinados em aves em crescimento, pois ocorre maior retenção de nitrogênio pelas aves para que ocorra crescimento do tecido protéico. Esta retenção é mais acentuada quando se faz correção pelas perdas endógenas e metabólicas.

Os valores de EMV foram em média 3,77\% maiores que os de EMA. Segundo Leeson \& Summers (2001), os valores de EMV não são afetados pela ingestão de alimentos e se mantêm sempre constantes, entretanto, os valores de EMA tendem a reduzir quando as aves apresentam baixa ingestão de ração. Sob baixo consumo (aproximadamente $50 \%$ da mantença), as perdas de energia metabólica fecal e urinária endógena assumem grande porção da energia da excreta. Os valores de EMA foram menores, entretanto, a

Tabela 2 - Composição nutriconal e valores de energia bruta dos alimentos, expressos na matéria natural ${ }^{1}$

\begin{tabular}{|c|c|c|c|c|c|c|c|c|}
\hline Alimento & MS (\%) & PB (\%) & $\mathrm{EE}(\%)$ & Cinzas (\%) & $\mathrm{Ca}(\%)$ & $\mathrm{P}(\%)$ & Mg (\%) & EB (kcal/kg) \\
\hline Trigo grão 1 & 88,27 & 11,40 & 1,84 & 1,62 & 0,01 & 0,31 & 0,04 & 3.821 \\
\hline Trigo grão 2 & 87,99 & 12,34 & 1,60 & 1,36 & 0,01 & 0,26 & 0,03 & 3.762 \\
\hline Farelo de trigo 1 & 87,91 & 13,01 & 3,97 & 4,45 & 0,15 & 0,88 & 0,55 & 3.839 \\
\hline Farelo de trigo 2 & 88,25 & 13,81 & 3,78 & 4,70 & 0,07 & 0,76 & 0,52 & 3.775 \\
\hline Milho grão 1 & 87,88 & 6,92 & 4,30 & 1,36 & 0,01 & 0,23 & 0,03 & 3.964 \\
\hline Milho grão 2 & 88,02 & 7,17 & 3,98 & 1,15 & 0,01 & 0,21 & 0,03 & 3.932 \\
\hline Sorgo grão & 87,58 & 7,90 & 2,64 & 1,33 & 0,03 & 0,20 & 0,15 & 3.741 \\
\hline $\begin{array}{l}\text { Farelo de glúten } \\
\text { de milho } 21 \%\end{array}$ & 87,13 & 21,27 & 2,13 & 5,31 & 0,03 & 0,85 & 0,56 & 3.819 \\
\hline
\end{tabular}

Tabela 3 - Composição nutricional e diâmetro geométrico médio das partículas (DGM) dos alimentos, expressos na matéria natural ${ }^{1}$

\begin{tabular}{|c|c|c|c|c|c|c|c|c|}
\hline \multirow[b]{2}{*}{ Alimento } & \multicolumn{8}{|c|}{ Nutriente (\%) } \\
\hline & FB & FDN & FDA & HEM & ENN & Amido & AS & DGM $(\mu \mathrm{m})$ \\
\hline Trigo grão 1 & 2,14 & 13,62 & 3,05 & 10,57 & 71,26 & 48,33 & 4,02 & 616,92 \\
\hline Trigo grão 2 & 2,27 & 13,64 & 2,92 & 10,72 & 70,41 & 50,10 & 4,08 & 641,70 \\
\hline Farelo de trigo 1 & 9,42 & 40,49 & 11,69 & 28,89 & 57,06 & 32,11 & 5,95 & 418,20 \\
\hline Farelo de trigo 2 & 9,57 & 40,65 & 11,65 & 28,91 & 56,39 & 32,13 & 5,87 & 500,52 \\
\hline Milho grão 1 & 1,93 & 12,55 & 3,38 & 9,17 & 73,36 & 59,21 & 4,61 & 569,97 \\
\hline Milho grão 2 & 1,87 & 11,62 & 2,80 & 8,82 & 73,84 & 59,62 & 5,06 & 598,91 \\
\hline Sorgo grão & 2,42 & 10,03 & 3,00 & 7,04 & 73,29 & 55,47 & 3,77 & 542,83 \\
\hline $\begin{array}{l}\text { Farelo glúten } \\
\text { milho } 21 \%\end{array}$ & 8,83 & 36,18 & 9,31 & 26,87 & 49,59 & 19,89 & 4,84 & 445,02 \\
\hline
\end{tabular}

${ }^{1}$ HEM = hemicelulose; ENN = extrativo não-nitrogenado; amido; $A S$ = açúcares solúveis e DGM (expresso em $\mu$ m). 
metodologia utilizada foi a de coleta total de excretas, na qual as aves são alimentadas à vontade e conseqüentemente, os valores de EMA e EMV deveriam ser próximos.

Os valores energéticos corrigidos pelo balanço de nitrogênio comprovaram redução de aproximadamente

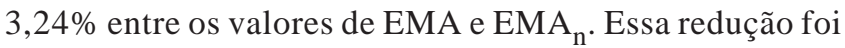
menor quando comparados os valores médios de EMV e $\mathrm{EMV}_{\mathrm{n}}$, que apresentaram diferença $0,45 \%$ menor para os valores de $\mathrm{EMV}_{\mathrm{n}}$. Segundo Leeson \& Summers (2001), na maioria das situações, é necessário corrigir todos os valores estimados de energia pelo balanço de nitrogênio. Durante o ensaio de metabolismo, é impossível assegurar que todas as aves apresentem a mesma taxa de crescimento, tornando-se necessária a correção para o balanço de nitrogênio.

Os valores de $\mathrm{EMA}_{\mathrm{n}}$ são utilizados diretamente na formulação de rações para aves. Considerando a média dos valores de EMA $_{n}$ dos ingredientes estudados, verificou-se pequena variação entre os valores das tabelas de Rostagno et al. (2005), da EMBRAPA (1991) e do NRC (1994). Os farelos de trigo estudados apresentaram valores semelhantes aos descritos por Rostagno et al. (2005) e Janssen (1989). Entretanto, para os trigos 1 e 2, os milhos 1 e 2, o sorgo e o farelo de glúten de milho $21 \%$, os valores de $\mathrm{EMA}_{\mathrm{n}}$ foram inferiores aos obtidos por Rostagno et al. (2005), EMBRAPA (1991), MAARA (1996) e NRC (1994).
Os trigos e os milhos tiveram valores de $\mathrm{EMV}_{\mathrm{n}}$ próximos aos das tabelas de Rostagno et al. (2005) e NRC (1994). Para o sorgo e o farelo de glúten de milho $21 \%$, os valores de $\mathrm{EMV}_{\mathrm{n}}$ foram inferiores aos citados por NRC (1994) e Rostagno et al. (2005). Os valores dos farelos de trigo 1 e 2 foram inferiores aos propostos por Rostagno et al. (2000) e superiores aos descritos pelo NRC (1994).

Segundo Parsons et al. (1982), os valores de EMV são sempre elevados e, conseqüentemente, os valores de $\mathrm{EMA}_{\mathrm{n}}$ parecem ser mais coerentes para predizer a EM dos alimentos.

Os ingredientes diferiram significativamente $(\mathrm{P}<0,05)$ quanto aos coeficientes de metabolizabilidade (Tabela 5). Os alimentos com alto teor de FB apresentaram menores coeficientes de metabolizabilidade, comprovando a baixa digestibilidade da FB no trato gastrointestinal das aves. Segundo Penz Jr. et al. (1999), o alto teor de FB nos alimentos, principalmente nos derivados do trigo, tende a provocar diminuição no consumo de ração pelas aves e na estimativa dos valores energéticos, tendência que aumenta de acordo com a porcentagem desses alimentos nas rações.

Os conteúdos energéticos do milho, do sorgo e do trigo não diferiram estatisticamente $(\mathrm{P}>0,05)$. Segundo Lima (2001), o trigo contém inibidores de $\alpha$-amilase que, apesar de não terem sido totalmente identificados, sabe-se, são proteínas e se encontram principalmente no amido. As

Tabela 4 - Valores de energia metabolizável aparente (EMA), aparente corrigida $\left(E M A_{n}\right)$, verdadeira (EMV) e verdadeira corrigida $\left(\mathrm{EMV}_{\mathrm{n}}\right)^{1}(\mathrm{kcal} / \mathrm{kg}$ de MS)

\begin{tabular}{|c|c|c|c|c|}
\hline Alimento & EMA & $\mathrm{EMA}_{\mathrm{n}}$ & EMV & $\mathrm{EMV}_{\mathrm{n}}$ \\
\hline Trigo grão 1 & $3.317 \pm 119$ & $3.210 \pm 72$ & $3.413 \pm 125$ & $3.409 \pm 138$ \\
\hline Trigo grão 2 & $3.465 \pm 82$ & $3.339 \pm 52$ & $3.576 \pm 75$ & $3.582 \pm 81$ \\
\hline Farelo de trigo 1 & $2.108 \pm 172$ & $2.019 \pm 182$ & $2.221 \pm 172$ & $2.180 \pm 192$ \\
\hline Farelo de trigo 2 & $2.044 \pm 196$ & $1.972 \pm 156$ & $2.169 \pm 196$ & $2.111 \pm 210$ \\
\hline Milho grão 1 & $3.924 \pm 55$ & $3.830 \pm 117$ & $4.055 \pm 47$ & $4.122 \pm 48$ \\
\hline Milho grão 2 & $3.799 \pm 130$ & $3.705 \pm 152$ & $3.907 \pm 27$ & $3.957 \pm 38$ \\
\hline Sorgo grão & $3.551 \pm 76$ & $3.464 \pm 71$ & $3.652 \pm 81$ & $3.680 \pm 90$ \\
\hline Farelo de glúten de milho $21 \%$ & $1.992 \pm 116$ & $1.901 \pm 99$ & $2.117 \pm 124$ & $1.961 \pm 147$ \\
\hline
\end{tabular}

${ }^{1}$ Valores expressos em $\mathrm{kcal} / \mathrm{kg}$ de MS.

2 Erro-padrão.

Tabela 5 - Coeficientes de metabolizabilidade da energia metabolizável aparente (CMA), aparente corrigida $\left(\mathrm{CMA}_{\mathrm{n}}\right)$, verdadeira $(\mathrm{CMV})$ e verdadeira corrigida $\left(\mathrm{CMV}_{\mathrm{n}}\right)$ dos alimentos

\begin{tabular}{|c|c|c|c|c|}
\hline Alimento & CMA & $\mathrm{CMA}_{\mathrm{n}}$ & CMV & $\mathrm{CMV}_{\mathrm{n}}$ \\
\hline Trigo grão 1 & $76,62 \mathrm{a} \pm 2,75$ & $74,15 a \pm 2,54$ & $78,86 a \pm 2,88$ & $78,75 a \pm 3,18$ \\
\hline Trigo grão 2 & $81,05 a \pm 1,92$ & $78,11 \mathrm{a} \pm 1,68$ & $83,64 a \pm 1,75$ & $83,78 \mathrm{a} \pm 1,90$ \\
\hline Farelo de trigo 1 & $49,27 b \pm 3,95$ & $46,24 b \pm 3,47$ & $50,86 b \pm 3,93$ & $49,92 b \pm 4,40$ \\
\hline Farelo de trigo 2 & $47,79 b \pm 4,59$ & $46,10 \mathrm{~b} \pm 4,26$ & $50,72 b \pm 4,58$ & $49,35 b \pm 4,91$ \\
\hline Milho grão 1 & $87,00 \mathrm{a} \pm 1,23$ & $84,91 \mathrm{a} \pm 1,15$ & $89,90 a \pm 1,05$ & $91,38 \mathrm{a} \pm 1,07$ \\
\hline Milho grão 2 & $85,03 a \pm 2,91$ & $82,93 a \pm 2,63$ & $87,45 a \pm 2,84$ & $88,57 \mathrm{a} \pm 3,09$ \\
\hline Sorgo grão & $83,11 \mathrm{a} \pm 1,79$ & $81,09 a \pm 1,66$ & $85,49 a \pm 1,89$ & $86,14 a \pm 2,10$ \\
\hline Farelo de glúten milho $21 \%$ & $45,45 b \pm 2,65$ & $43,37 b \pm 2,27$ & $48,29 b \pm 2,84$ & $44,74 b \pm 3,34$ \\
\hline CV (\%) & 10,51 & 9,82 & 10,17 & 11,26 \\
\hline
\end{tabular}

Médias seguidas pela mesma letra na coluna não diferem $(P<0,05)$ pelo teste de SNK.

1 Erro-padrão. 
pentosanas solúveis do trigo têm efeito negativo sobre a digestibilidade do amido, da proteína e dos lipídeos nas dietas de aves (Choct et al., 1992) e, conseqüentemente, afetam a metabolizabilidade da energia desse alimento.

\section{Conclusões}

Os valores de EMA e EMA ${ }_{\mathrm{n}}$, expressos em $\mathrm{kcal} / \mathrm{kg}$ de MS, foram em média de 3.391 e 3.275 para o trigo grão, de 2.076 e 1.996 para o farelo de trigo, de 3.862 e 3.768 para o milho grão, de 3.551 e 3.464 para o sorgo grão e de 1.992 a 1.901 para o farelo de glúten de milho $21 \%$. Os valores de EMV e EMV $\mathrm{n}_{\mathrm{n}}$, expressos em kcal/kg de MS, foram em média de 3.495 e 3.496 para o trigo grão, de 2.195 e 2.146 para o farelo de trigo, de 3.981 e 4.040 para o milho grão, de 3.652 e 3.680 para o sorgo grão e de 2.117 a 1.961 para o farelo de glúten de milho $21 \%$. Os valores médios dos coeficientes de metabolizabilidade foram de 79,37\% para o trigo grão, de $48,78 \%$ para o farelo de trigo, de $87,15 \%$ para o milho grão, de $83,96 \%$ para o sorgo grão e de $45,46 \%$ para o farelo de glúten de milho $21 \%$.

\section{Literatura Citada}

ALBINO, L.F.T.; SILVA, M.A. Valores nutritivos de alimentos para aves e suínos determinados no Brasil. In: SIMPÓSIO INTERNACIONAL SOBRE EXIGÊNCIAS NUTRICIONAIS DE AVES E SUÍNOS, 1996, Viçosa, MG. Anais... Viçosa, MG: Universidade Federal de Viçosa, 1996. p.303-318.

BARTOV, I. Lack of interrelationship between the effects of dietary factors and food with drawal on carcass quality of broiler chickens. Bristish Poultry Science, v.39, p.426-433, 1998.

BRUGALLI, I.; ALBINO, L.F.T.; SILVA, D.J. et al. Efeito do tamanho de partícula e do nível de substituição nos valores energéticos da farinha de carne e ossos para pintos de corte. Revista Brasileira de Zootecnia, v.28, n.4, p.753-757, 1999.

CHOCT, M.; ANNISON, G.; TRIMBLE, R. Soluble wheat pentosanas exhibit different anti-nutritive activies in intact and cecectomized broiler chickens. Journal of Nutrition, v.122, p.2457-2465, 1992.

EMPRESA BRASILEIRA DE PESQUISA AGROPECUÁRIA EMBRAPA. Tabela de composição química e valores energéticos de alimentos para suínos e aves. 3.ed. Concórdia: EMBRAPA-CNPSA, 1991. 97p. [Documento 19].

FREITAS, E.R.; SAKOMURA, N.K.; EZEQUIEL, J.M.B.; et al. Energia metabolizável de alimentos na formulação de ração para frangos de corte. Pesquisa Agropecuária Brasileira, v.41, n.1, p.107-115, 2006.

HALL, M.B. Neutral detergent-soluble carbohydrates nutritional relevance and analysis. A laboratory manual. Gainesville: University of Florida, 2000. 39p. (Bulletin, 339).

HILL, F.W.; ANDERSON, D.L. Comparison of metabolizable energy and produtive energy determinations whit growing chicks. Journal of Nutrition, v.64, n.3, p.587-604, 1958.

JANSSEN, W.M.A. European table of energy values poultry feedstuffs. 3.ed. Beekbergen: Spelderholt Center for Poultry Research and Information Services, 1989. 84p.
KOLLING, A.V.; KESSLER, A.M.; RIBEIRO, A.M.L. Desempenho e composição corporal de frangos de corte alimentados com diferentes níveis de proteína e de aminoácidos ou com livre escolha das dietas. Revista Brasileira de Zootecnia, v.34, n.1, p.98103, 2005.

LEESON; S.; SUMMERS, J.D. Scott's nutrition of the chicken. 4.ed. Guelph: University Books, 2001. 591p.

LIMA, G.J.M.M. Ingredientes energéticos: trigo e triticale na alimentação animal. In: SIMPÓSIO SOBRE INGREDIENTES NA ALIMENTAÇÃO ANIMAL, 2001, Campinas. Anais... Campinas: 2001. p.33-76.

LIMA, I.L. Níveis nutricionais utilizados nas rações pela indústria avícola. In: SIMPÓSIO INTERNACIONAL SOBRE EXIGÊNCIAS NUTRICIONAIS DE AVES E SUÍNOS, 1996, Viçosa, MG. Anais... Viçosa, MG: Universidade Federal de Viçosa, 1996. p.389-402.

MATTERSON, L.D.; POTTER, L.M.; STUTZ, M.W. et al. The metabolizable energy of feed ingredients for chickens. Storrs: University of Connecticut Storrs, 1965. v.11, p.3-11. (Agricultural Experiment Station Research Report).

MINISTÉRIO DA AGRICULTURA, DO ABASTECIMENTO E DA REFORMA AGRÁRIA - MAARA. Normas e padrões de nutrição e alimentação animal. Brasília: 1996. 145p. (Revisão 96).

NATIONAL RESEARCH COUNCIL - NRC. Nutrient requirements of poultry. 9.ed. Washington, D.C.: National Academy of Sciences, 1994. 155p.

NATIONAL RESEARCH COUNCIL - NRC. Nutrient requirements of swine. 10.ed. Washington, D.C: National Academy of Sciences, 1998. 189p.

NUNES, R.V.; ROSTAGNO, H.S.; ALBINO, L.F.T. et al. Composição bromatológica, energia metabolizável e equações de predição da energia do grão e de subprodutos do trigo para pintos de corte. Revista Brasileira de Zootecnia, v.30, n.3, p.774-784, 2001.

PARSONS, C.M.; POTTER, L.M.; BROWN, J.R. Effects of dietary protein and intestinal microflora and excretion of amino acids in poultry. Poultry Science, v.61, n.3, p.639-645, 1982.

PENZ JR., A.M.; KESSLER, A.M.; BRUGALLI, I. Novos conceitos de energia para aves. In: SIMPÓSIO INTERNACIONAL SOBRE NUTRIÇÃO DE AVES, 1999, Campinas. Anais... Campinas: Fundação Apinco de Ciência e Tecnologia Avícolas, 1999. p.1-24.

ROSTAGNO, H.S.; ALBINO, L.F.T.; DONZELE, J.L. et al. Tabelas brasileiras para aves e suínos: composição de alimentos e exigências nutricionais de aves e suínos (Tabelas brasileiras). 2.ed. Viçosa, MG: Universidade Federal de Viçosa, 2005. 186p.

ROSTAGNO, H.S.; ALBINO, L.F.T.; DONZELE, J.L. et al. Tabelas brasileiras para aves e suínos: composição de alimentos e exigências nutricionais. Viçosa, MG: Universidade Federal de Viçosa, 2000. 141p.

SAID, N. Processamento por extrusão de ingredientes e rações. In: SIMPÓSIO INTERNACIONAL SOBRE FABRICAÇÃO DE RAÇÕES, 1995, Curitiba. Anais... Curitiba: 1995. p.1-15.

SCOTT, M.L.; NESHEIM, M.C.; YOUNG, R.J. Nutrition of the chicken. 3.ed. Ithaca: M.L. Scott. Pass, 1982. 520p.

SIBBALD, I.R. Measurement of bioavailable energy in poultry feedingstuffs: a review. Canadian Journal of Animal Science, v.62, n.4, p.983-1048, 1982.

SILVA, D.J.; QUEIROZ, A.C. Análise de alimentos (métodos químicos e biológicos). 2.ed. Viçosa, MG: Editora UFV, 2002. 235p.

UNIVERSIDADE FEDERAL DE VIÇOSA - UFV. Manual de utilização do programa SAEG (Sistema para Análise Estatísticas e Genéticas). Viçosa, MG: 1999. 59p.

ZANOTTO, D.L.; BELLAVER, C. Método de determinação da granulometria de ingredientes para uso em rações de suínos e aves. Concórdia: Embrapa Suínos e Aves, 1996. p.1-5. (Comunicado Técnico). 